\title{
Notes on the vocalizations of Groundscraper Thrush (Psophocichla litsitsirupa)
}

\section{Peter Boesman}

In the following we briefly analyze and compare voice of the different races of Groundscraper Thrush (Psophocichla litsitsirupa). We also try to quantify the extent of any vocal differences using the criteria proposed by Tobias et al. (2010), as a support for taxonomic review. We have made use of sound recordings available on-line from Xeno Canto (XC) and Macaulay Library (ML).

We are mainly interested in comparing the voice of the disjunct Abyssinian population with other races. An overview of vocalizations, illustrated with sonograms:

\section{Ethiopia (simensis)}

song
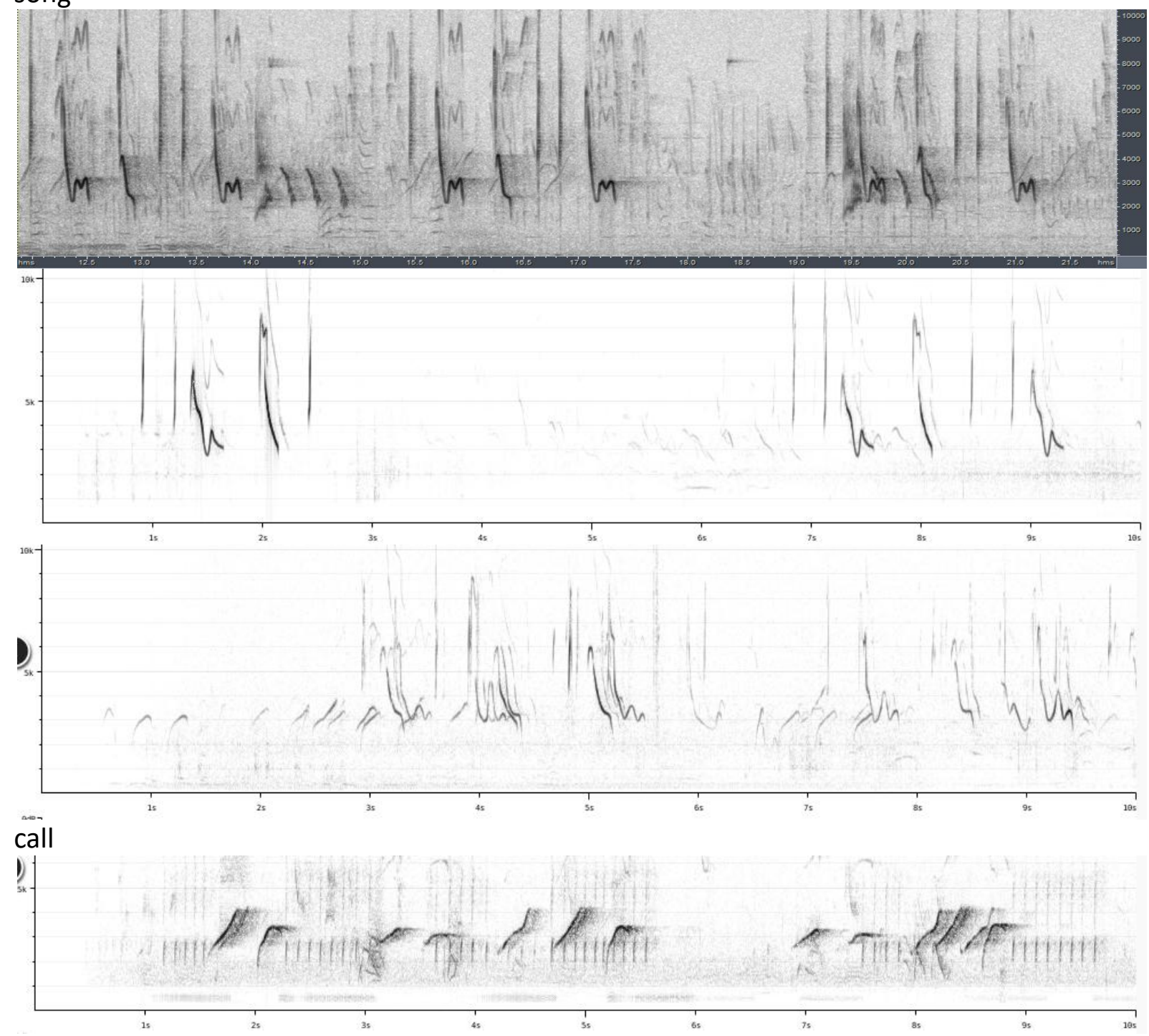
HANDBOOK OF THE

BIRDS PF, THE WORLD

ORNITHOLOGICAL NOTES

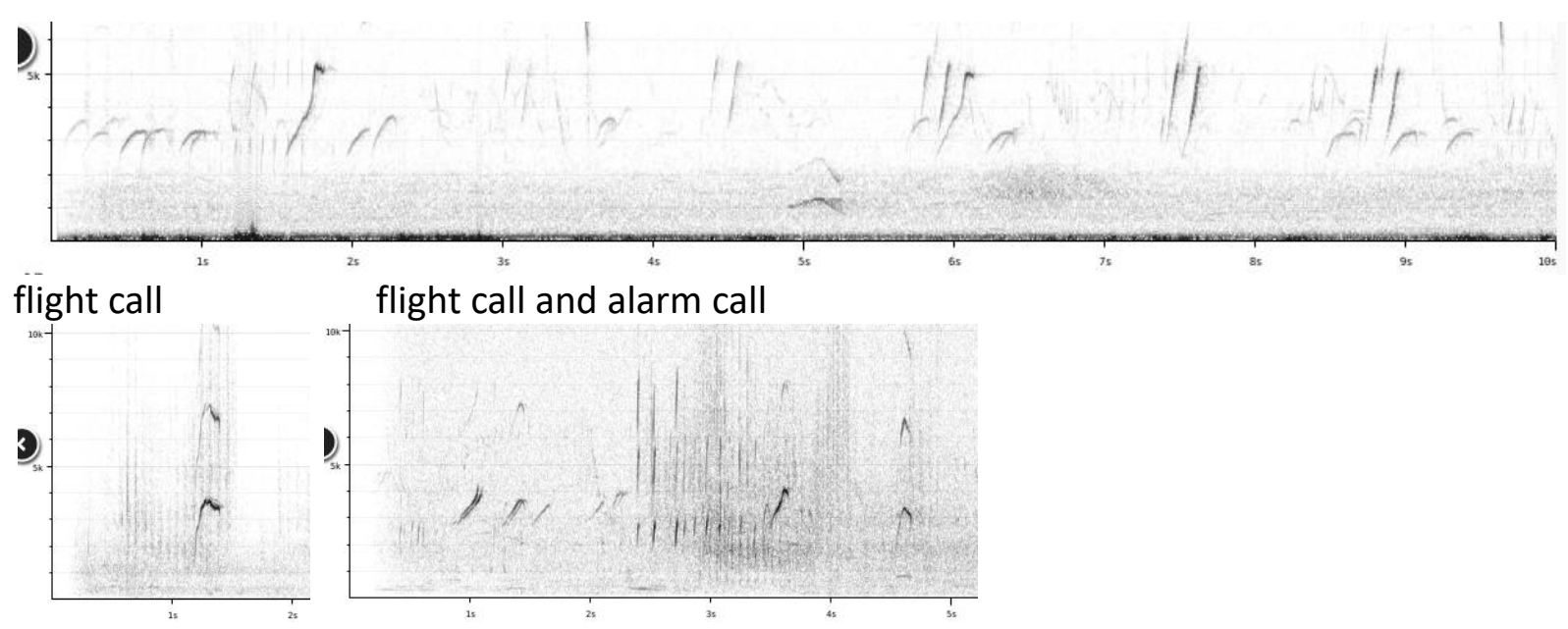

Other races

song

South Africa

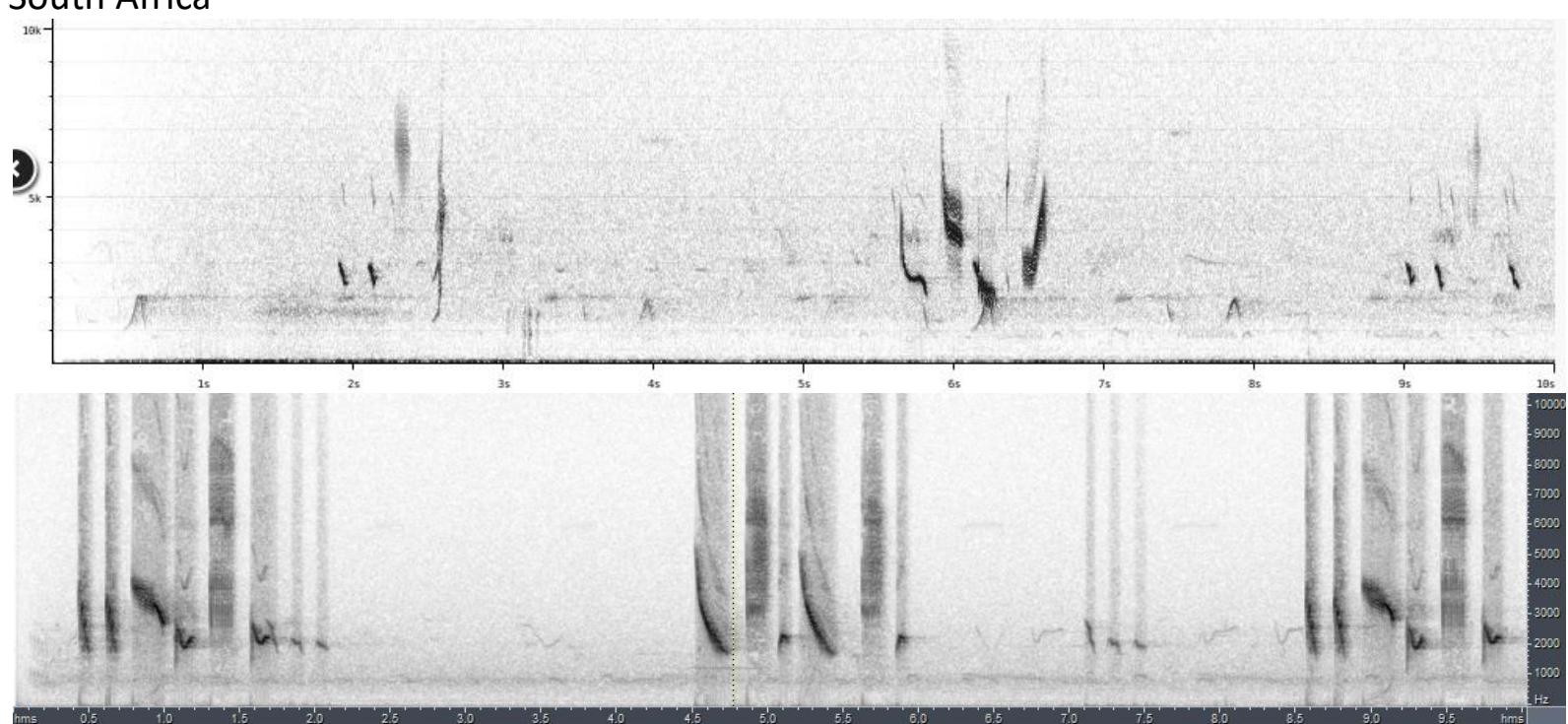

Namibia
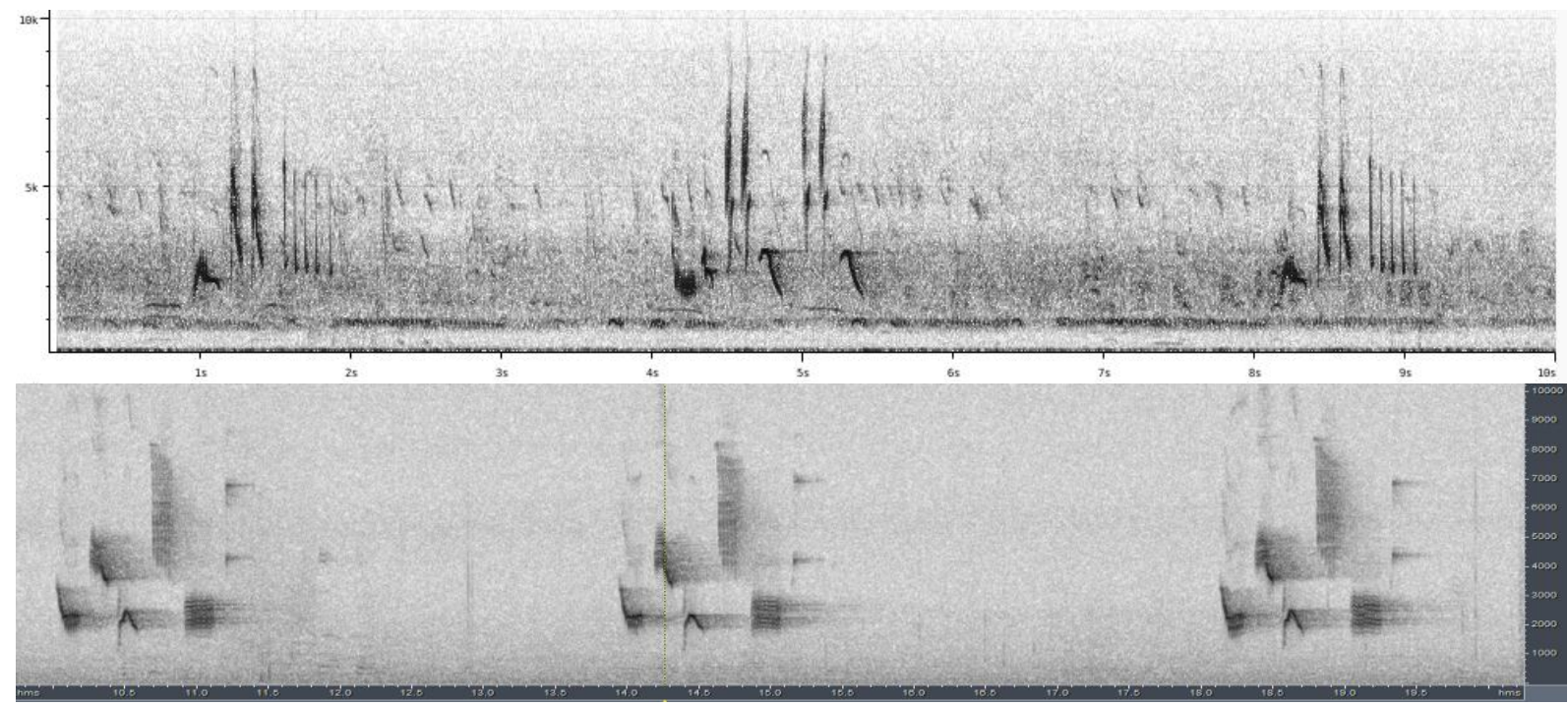

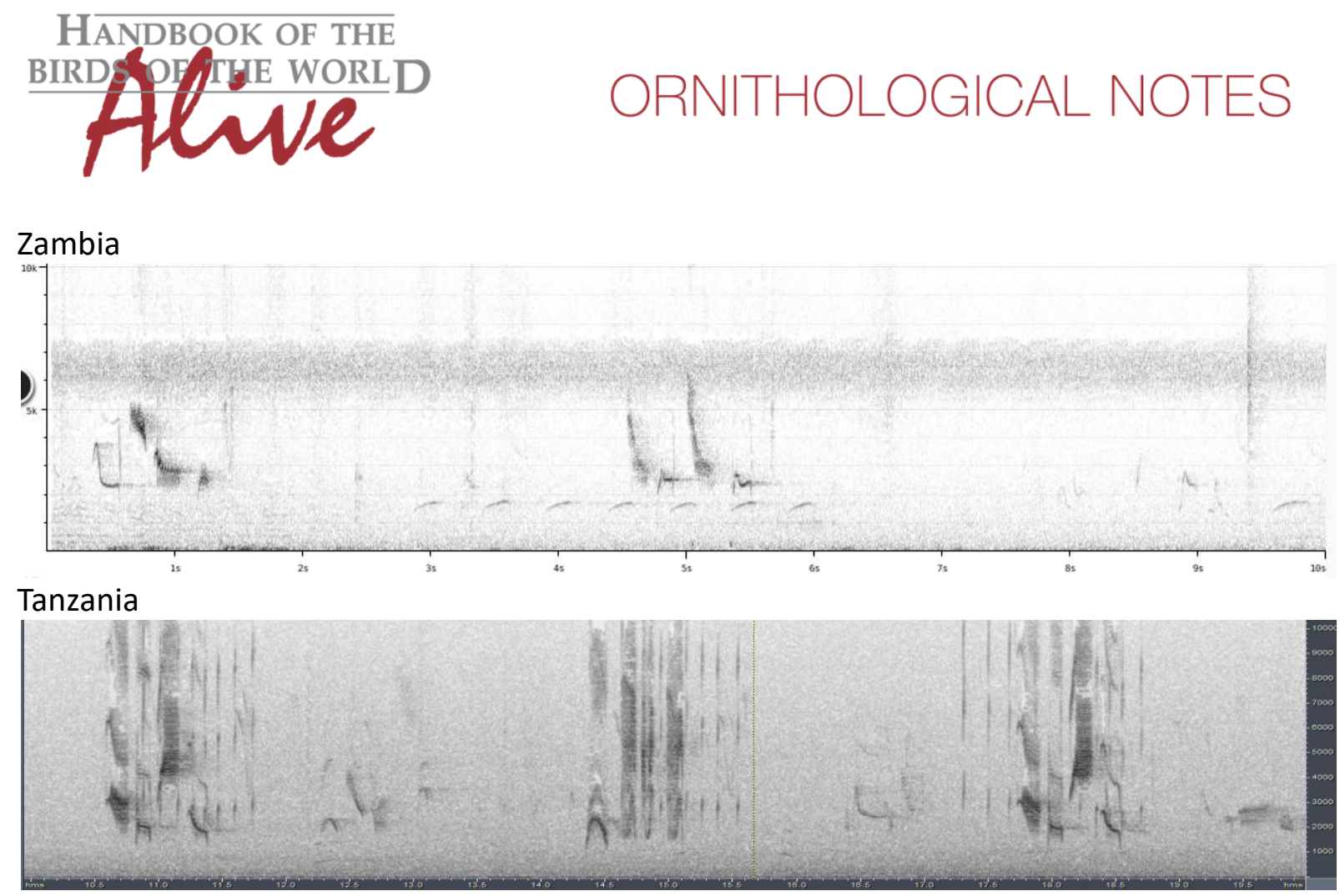

Song of simensis lacks to a large extent the rich throaty 'thrush-whistles'. Song consists mainly of sharp 'tsik' calls and fairly high-pitched pure sharply downslurred whistles. Only very rarely a more throaty whistle is thrown in. Overall sounding very 'un-thrush-like'. Song of other races is just the opposite, consisting mainly of the lower-pitched rich throaty 'thrush-whistles', and only occasionally a sharper 'tchek' call or a pure downslurred whistles. Overall sounding very 'thrush-like'

We have quite a few recordings of calls of simensis, unfortunately only a rattling alarm call of other races. No comparison possible here.

All in all, it would seem that simensis and other races share a number of notes in their vocabulary, but the frequency of use in their song is totally different (cfr. Sirystes case). We could score vocal difference of simensis based e.g. on the higher pitched notes (only a few reaching below $2.5 \mathrm{kHz}$ vs. many)(score 2 ) and the much higher percentage of pure whistles (vs. many throaty whistles) (score 1-2). This would lead to a total vocal score of about 3-4.

Given there are relatively few recordings available, tt would be good to have these conclusions confirmed by more recordings.

This note was finalized on 3rd May 2016, using sound recordings available on-line at that moment. We would like to thank in particular the sound recordists who placed their recordings for this species on XC and ML: Peter Boesman, Rolf de By, Frank Lambert, Linda Macaulay, David Moyer, Rory Nefdt, Faansie Peacock, Niall Perrins and Bram Piot. 


\section{References}

Tobias, J.A., Seddon, N., Spottiswoode, C.N., Pilgrim, J.D., Fishpool, L.D.C. \& Collar, N.J. (2010). Quantitative criteria for species delimitation. Ibis 152(4): 724-746.

\section{Recommended citation}

Boesman, P. (2016). Notes on the vocalizations of Groundscraper Thrush (Psophocichla litsitsirupa). HBW Alive Ornithological Note 303. In: Handbook of the Birds of the World Alive. Lynx Edicions, Barcelona. (retrieved from http://www.hbw.com/node/1251759 on 14 October 2016). 